\title{
The Rise of Antimicrobial Resistance in Mass Gatherings
}

\author{
Hamid Bokhary, Harunor Rashid, Grant A. Hill-Cawthorne, and \\ Moataz Abd El Ghany
}

\section{Contents}

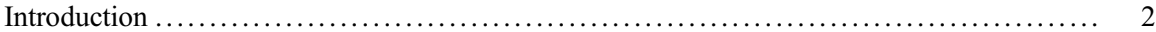

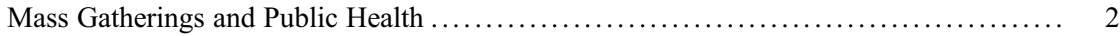

Global Concern of Antimicrobial Resistance ................................. 3

Arab World, Antimicrobial Resistance, and Mass Gatherings ...................... 4

Infectious Diseases in the Arab World ...................................... 4

The Rise of Antimicrobial Resistance in Mass Gatherings .......................... 6

Impact of Hajj on the Transmission of Drug-Resistant Infections .................. 7

Drug-Resistant Enteric Infections at Hajj .................................... 8

Mobile Nature of Resistance Genes Found in Hajj Mass Gathering . . . . . . . . . . . . . . . 9

Drug Resistant Respiratory Infections in Hajj ................................. 10

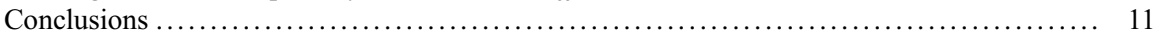

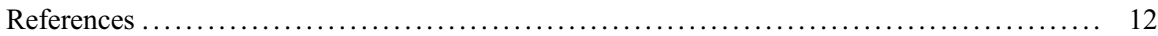

H. Bokhary $(\bowtie)$

Umm Al-Qura University, Makkah, Saudi Arabia

School of Public Health, The University of Sydney, Sydney, NSW, Australia e-mail: hamid.bokhary@sydney.edu.au; hamidbokhary@outlook.com

H. Rashid

National Centre for Immunisation Research and Surveillance (NCIRS), Kids Research at The Children's Hospital at Westmead, Westmead, NSW, Australia

The Marie Bashir Institute for Infectious Diseases and Biosecurity, The University of Sydney, Sydney, Australia

e-mail: harunor.rashid@sydney.edu.au

G. A. Hill-Cawthorne

School of Public Health, The University of Sydney, Sydney, NSW, Australia e-mail: grant.hill-cawthorne@sydney.edu.au

M. Abd El Ghany

The Westmead Institute for Medical Research, The University of Sydney, Sydney, Australia

The Marie Bashir Institute for Infectious Diseases and Biosecurity, The University of Sydney, Sydney, Australia

e-mail: moataz.mohamed19@outlook.com; moataz.mohamed@sydney.edu.au 


\section{Abstract}

Mass gatherings (MGs) are a common human group behavior. Antimicrobial resistance (AMR) is a major public health issue. The Arab world hosts the annual Hajj pilgrimage, a MG with diverse attendees, and the region is also a layover hub for global travels. Although AMR surveillance is still insufficient, the available data on Hajj reveal that the AMR rate is generally high and is increasing each year. Enteric infections are common in Hajj and provide grounds for AMR acquisition and transmission, including emerging resistance to $\beta$-lactams. Respiratory infections are a major concern in Hajj, where incidences of outbreaks such as meningococcal disease being documented during the pilgrimage. With the recorded high usage of antimicrobials during Hajj, including mandatory prophylaxis for high-risk travelers and the availability of over-the-counter antimicrobials, the risk of AMR development is likely to increase.

\section{Keywords}

Mass gathering $\cdot$ Antimicrobial resistance $\cdot$ Arab $\cdot$ Health $\cdot$ Hajj

\section{Introduction}

\section{Mass Gatherings and Public Health}

The tendency to gather in large numbers is an ancient human behavior, driven by a collective desire to express presence in unity. Mass gatherings (MGs) have long been documented to have an impact on the health of participants and on the host country's infrastructure and economy (Horwitz et al. 1977). Managing health risks that MGs pose is a long-known practice for health authorities, such as the temporary suspension of pilgrimage for British Hajj participants as a preventive measure against cholera at the end of the nineteenth century (Vintras 1894). The term "Mass Gathering Medicine" (MGM) has appeared more frequently in recent years in medical and public health literature (De Lorenzo et al. 1993). Many peaceful MGs have attracted millions of people: the largest peaceful gatherings in history have been the 2013 Kumbh Mela pilgrimage (India, 30 million participants); the 2014 Arbaeen festival (Iraq, 20 million participants); the funeral of $\mathrm{CN}$ Annadurai, 1969 (India, $\sim 15$ million participants); the funeral of Ayatollah Khomeini, 1989 (Iran, $\sim 10$ million participants); the Papal Mass in the Philippines (2015, 6 million participants); the 1995 World Youth Day (the Philippines, $\sim 5$ million participants); the funeral of Egyptian President Gamal Abdel Nasser, 1970 (Egypt, 5 million participants); the funeral of Pope John Paul II, 2005 (Italy, 4 million participants); Rod Stewart concert, 1994 (Brazil, 3.5 million participants); the 2012 Hajj pilgrimage (KSA, $\sim 3$ million participants), and an anti-war march, 2003 (Italy, 3 million participants).

The World Health Organization (WHO) has defined MG as a gathering of "more than a specified number of persons (which may be as few as 1000 persons although 
much of the available literature describes gatherings exceeding 25,000 persons) at a specific location for a specific purpose (a social function, large public event or sports competition) for a defined period of time" (Michael and Barbera 1997; WHO 2008). MGs have been associated with changes in population dynamics that strain the existing infrastructures that in turn can result in changes in the health and behavior of participants (WHO 2015a). MGs represent a platform for varied health risks, including the transmission of infectious diseases (e.g., foodborne outbreaks), adverse effects associated with environmental exposure (e.g., heat exhaustion and stroke), and other noncommunicable health risks (e.g., crushes, stampedes, cardiovascular events).

Many studies have highlighted the emergence and transmission of infectious diseases during planned MGs, including sporting (Gautret and Steffen 2016; Pesola et al. 2015), cultural events (Gautret and Steffen 2016; Grgic-Vitek et al. 2015), and religious events (Gautret and Steffen 2016; Pfaff et al. 2010). Although all types of planned MGs can raise public health threats, the implications on public health vary depending upon a multitude of interrelated factors. The key factors that determine the potential impact of a MG on public health include: type of the event; duration; origin, density, and health status of the participants; venue characteristics; demographics of participants and activities performed; and status of public health in the host community/country. For instance, MGs that attract international participants can increase the risk of importing infectious diseases into the host country and the risk of exporting such infectious agents when the participants return to their countries of origin. The magnitude of this impact depends on the number of participants, their countries of origin, their background immunity, and the health risks endemic to the host country (Abd El Ghany et al. 2018; Gautret et al. 2015; Gautret and Steffen 2016).

Therefore, the WHO has recommended that the activities of a planned MG should meet the requirements of the International Health Regulations (IHR) 2005 for enhancing global health security and preventing the transmission of infectious diseases (WHO 2015a; WHO Secretariat 2011).

Recently, the WHO has reported on the high prevalence of antimicrobial resistance (AMR) among pathogens responsible for the most common hospital- and community-acquired infections in all regions of the world (WHO 2014). The global transmission of AMR-pathogens is in turn fueled by AMR-carriage associated with human displacement and international travel (de Smalen et al. 2017). A proportion of this global travel includes the large numbers of domestic and international travelers who participate in MGs (WHO 2016). Prolonged AMR-carriage, lasting up to 1 year after returning from endemic regions, has been reported (Arcilla et al. 2017).

\section{Global Concern of Antimicrobial Resistance}

The discovery of penicillin in 1928 (Fleming 1929) and subsequent development of other broad-spectrum antimicrobials revolutionized twentieth and twenty-first century medicine. However, following the development of fluoroquinolones in the early 
1970s, no major groups of antibacterial drugs have been developed. This paucity in development coincides with an increasing threat of antimicrobial resistant organisms. Humans now face a significant risk of a post-antimicrobial era of medicine, in which common infections can kill once more (Chan 2011).

AMR is a major threat to global public health. Every year, 700,000 deaths are attributed to AMR-resistant infections (O’Neill 2016) with low- and middle-income countries being the most affected, both in terms of impact on public health and economic burden. The global mortality associated with drug resistance is projected to be ten million per year by 2050 if the current prevalence rate remains unaltered, with an economic loss of up to US\$100 trillion (O’Neill 2014).

Antimicrobials are used in a variety of applications such as in agriculture (Khachatourians 1998) and livestock farming (Pagel and Gautier 2012). Food provision has always been a priority for humans and with a growing population and industry demands, food providers use antimicrobials in the production process to allow for fast, product-secure, and cost-effective production. This has led to the acquisition or development of AMR in livestock animals' flora (Brown et al. 2017). Global efforts have risen to tackle this issue, such as the European Union ban on the use of growth-promoting antibiotics in livestock (Phillips 2007). Moreover, for food security, the WHO has issued guidelines on antimicrobial usage in food-producing animals (WHO 2017c).

\section{Arab World, Antimicrobial Resistance, and Mass Gatherings}

Terms used for searching the literature for the "Arab world" were: Saudi Arabia* or United Arab Emirates or UAE or Dubai or Egypt* or Arab* or Algeria* or Iraq* or Qatar* or Kuwait* or Morocco* or Oman* or Libya* or Sudan* or Syria* or Tunisia* or Lebanon* or Yemen* or Jordan* or Bahrain* or Palestine* or Mauritania* or Chad* or Comoro* or Djibouti* or Eritrea* or Israel* or Somali* or South Sudan*.

Terms used for searching for "AMR" were: methicillin-resistant* or drug resistant $*$ or antimicrobial resistant $*$ or antibacteria $*$ or antimicrobial $*$ or resistant $*$ or sensitive* or super or bug or multiresistant* or multi-resistant* or virulant* or antibiotic resistant*.

Terms used for searching for "MGs" were: Hajj or Arba'een or Haj or Hadj or tourism or world cup or Olympic* or mass gathering* or pilgrim* or Ziyar* or crowd $*$ or Imam Hussein $*$.

\section{Infectious Diseases in the Arab World}

The Arab world refers to the geographic region in which Arabic is the primary language, usually formed by northern Africa and western Asia. Recent conflicts in the region and the unique social and political structures that are present have led to the gradual deprioritization of healthcare services. Due to ongoing regional conflicts 
and the effect of the so-called Arab Spring (Coutts et al. 2013), data reporting in the region has been compromised (WHO 2014). In particular, infectious disease surveillance requires considerable improvements in terms of breadth, depth, and efficiency.

As in most low- and middle-income countries, the Arab world experiences a significant health burden due to infectious diseases. Lower respiratory tract infections are the leading cause of death in low-income Arab countries and are within the top three and top five in middle- and high-income Arab countries, respectively (Rahim et al. 2014). Diarrheal diseases have been the second leading cause of death in low-income Arab countries for the past 20 years (Rahim et al. 2014).

Tuberculosis (TB) is endemic in sub-Saharan Africa and southeast Asia. The Arab world countries most affected by TB are Ethiopia, Somalia, Sudan, and South Sudan (incidence ranges from 82 to 270 per 100,000 population, and mortality ranges from 14 to 75 per 100,000 population), followed by Yemen and Algeria (incidence: $48-70$ per 100,000 population; mortality: $6.9-7.7$ per 100,000 population) (WHO 2017a). In contrast, the incidence of endemic malaria in the Arab world is declining but imported malaria is a concern in some countries. However, certain countries are going against this trend. For instance, Saudi Arabia's autochthonous cases increased from 29 in 2010 to 272 in 2016. The situation in Yemen has been deteriorating since 2015 due to the ongoing civil war, and also in South Sudan due to the cross-border displacement of refugees, which may be contributing to an increase in malaria burden in neighboring countries (WHO 2017d). Viral infections are usually self-limiting and associated with a lower fatality rate; however, the newly emerged Middle East Respiratory Syndrome-coronavirus (MERS-CoV) in 2012 has a high fatality rate and is threatening a public health crisis in the region. Around $82 \%$ of reported cases have been from Saudi Arabia, with 31\% of cases resulting from transmission in healthcare settings (WHO 2017b).

The speed of emergence of AMR in the region has been as alarming as infectious disease outbreaks. Even in the past year, strains of Klebsiella pneumoniae carrying $b l a_{\mathrm{OXA}-48-t y p e}$ and $b l a_{\mathrm{NDM}}$ gene for carbapenem-resistance have been detected in the United Arab Emirates (Moubareck et al. 2018), Saudi Arabia (Al-Zahrani and Alsiri 2018), and Iraq (Hussein 2017). Other than the rapid emergence seen, most rates of drug resistance are increasing, such as the annual rise in methicillin resistance among Staphylococcus aureus isolates in Kuwaiti Hospitals from 906 in 2011 to 1771 in 2015 (Udo and Boswihi 2017). The Arab world is a geographic center for much of the world's trade, transport, and commercial lines. Moreover, the region hosts one of the world's largest annual MGs (Hajj), during which people come from every continent to participate. The risk of importing and disseminating communicable diseases is concerning. Furthermore, with infectious diseases and their endemic profiles, the risk of AMR arises.

It is important to understand the AMR situation in the Arab world and in the MGs hosted therein. The WHO reports that for its Eastern Mediterranean Regional Office (EMRO), of which 19 of the 22 countries are from the Arab world, the rate of resistance for Escherichia coli isolates to third-generation cephalosporins ranges from $22 \%$ to $63 \%$, and resistance to fluoroquinolones from $21 \%$ to $62 \%$. Klebsiella 
pneumoniae resistance to third-generation cephalosporins is $22-50 \%$ and to carbapenems up to 54\%. Staphylococcus aureus resistance to $\beta$-lactams was $10-53 \%$ and penicillin resistance in Streptococcus pneumoniae was 13-34\%. Rates of fluoroquinolone resistance for nontyphoidal Salmonella spp. ranged from $2 \%$ to $49 \%$ and for Shigella spp. ranged from 3\% to 10\%. Finally, soaring resistance to third-generation cephalosporins is now being seen in Neisseria gonorrhoeae, with up to $12 \%$ now displaying reduced susceptibility. No more than four countries in the region reported their $\mathrm{AMR}$ rates to $\mathrm{EMRO}$ for any given organism; indicating a poor reporting system (WHO 2014).

AMR surveillance in the Arab world is affected by regional insecurity and a lack of governance and awareness. The region is known to be affected by civil uprisings and wars with massive human displacements in the region (WHO 2014). This has resulted in shifting the priority in health programs to secondary rather than primary and preventive health services. Until 2015, there was no active national level action plans in any of the EMRO countries (WHO 2015b). Moreover, some countries lack enforcement for their own prescription policies (Nasr et al. 2017), such as the availability of antimicrobials without a prescription (WHO 2015b). A general lack of national awareness of the risks of AMR is due to poor health promotion and literacy (WHO 2015b). Poor health services infrastructure contributes to the low quality of AMR surveillance, with little investment in AMR surveillance occurring in the region and laboratories not adequately equipped with accurate and comprehensive instruments for antimicrobial testing, in addition to the presence of counterfeit antimicrobials (WHO 2015b). A lack of collaboration and transparency in the region is affecting the sharing of AMR data and reporting processes (WHO 2015b), which needs to be addressed and measures enforced.

\section{The Rise of Antimicrobial Resistance in Mass Gatherings}

Health issues in MGs vary depending on various factors intrinsic and extrinsic to the events. Some factors are linked directly to health, such as the presence of comorbidities among the attendees, and some are indirectly related, such as the time of year the event takes place in and the level of environmental pollution in the host city. Due to the increased risk to global public health, the hosts of MG events are advised to collaborate with international stakeholders for a holistic approach to tackle such issues. The main MGs in the region of public health significance are Hajj and Arba'een, which are both annual. Arba'een in Karbala, Iraq, occurs 40 days

after the Day of Ashura, i.e., the day when Hussain ibn Ali, the grandson of Prophet Mohammad (peace be upon him) was martyred. It is a key Shia religious observance and attendees commemorate and mourn the loss of Hussain (Al-Lami et al. 2013). Studies published thus far on Arba'een describe health issues other than AMR (A1Lami et al. 2013; Ghasemian et al. 2016). Infectious disease reports on other MGs in the Arab world are scarce. The main body of literature available, although very limited, focuses on AMR only at Hajj. 


\section{Impact of Hajj on the Transmission of Drug-Resistant Infections}

Hajj, the annual pilgrimage by Muslims to Makkah, Saudi Arabia, attracts two to three million pilgrims from 190 countries, together with hundreds of thousands of Saudi Arabian residents every year, making it a unique MG event in terms of the sheer number of attendees, ethnolinguistic diversity of pilgrims, nature of performed activities, and the regularity of the event. These enormously diverse populations, physically demanding rituals (e.g., circumambulation, marching between hillocks and animal sacrificing) performed by them and the congested settings (crowded accommodation, prolonged stay in tents, use of shared facilities) facilitate emergence and dissemination of infectious diseases within the host country and beyond. Each year, Makkah hosts multiple religious congregations: Umrah, the minor pilgrimage, and Hajj, the major pilgrimage that takes place on specific days of the last month of lunar calendar. Umrah pilgrimage, unlike Hajj, occurs throughout the year but most festively during the month of Ramadan (the 9th month of the lunar year) and involves fewer rites (e.g., visiting the Holy Mosque in Makkah). With a plan to go up to 30 million in 2030, the number of offshore pilgrims for the Umrah season, around six million during 2016, is greater than that of Hajj (around two million for the same year) (Yezli et al. 2017a). The most intense congestion happens during the last 10 days of Ramadan, creating a Hajj-like situation. However, the impact of Umrah on the emergence and dissemination of infectious diseases is yet to be studied (Yezli et al. 2017a).

Hajj has already been associated in the literature with an increased risk of airborne, foodborne, bloodborne, and zoonotic infections (Ahmed et al. 2006). For instance, the Hajj pilgrimage has been associated with major intercontinental outbreaks of meningococcal diseases, first by serogroup A in 1987, and then by serogroup W in 2000 and 2001 Hajj seasons (Moore et al. 1989). This triggered the introduction of the mandatory meningococcal vaccination policy for all Hajj pilgrims (Abd El Ghany et al. 2016). Previously, Hajj was also associated with several major outbreaks of Vibrio cholerae, including the emergence of the severe seventh pandemic of the El Tor strain (Hu et al. 2016). Recently, there have been concerns that Hajj may act as a focal point for the acquisition, emergence, and dissemination of AMR infections (Abd El Ghany et al. 2017; Leangapichart et al. 2016b; Olaitan et al. 2015). Multiple studies have demonstrated that pilgrims are at a higher risk of acquiring and transmitting AMR pathogens, including multidrugresistant Acinetobacter spp., carbapenemase-producing E. coli (Leangapichart et al. 2016b), and extended-spectrum cephalosporin- and colistin-resistant nontyphoidal Salmonella spp. (Olaitan et al. 2015). Acinetobacter baumannii was isolated from $14.4 \%$ throat only, $25.6 \%$ rectal only, and $3.3 \%$ of both throat and rectal swabs from French pilgrims returning after Hajj. All A. baumannii isolated were found to be bla $a_{\text {OXA-51-like }}$ gene positive and therefore ceftriaxone-resistant (Leangapichart et al. 2016b). Acquisition of bla ${ }_{\mathrm{CTX}-\mathrm{M}}$ genes also occurred during Hajj, with $32.6 \%$ of French pilgrims' stool samples being positive for this gene after Hajj compared to $5.5 \%$ before (Leangapichart et al. 2017). 


\section{Drug-Resistant Enteric Infections at Hajj}

A response to the 1997 Mina fire was for the Hajj authorities to ban pilgrims from cooking their own food (Ahmed et al. 2006). Pilgrims' meals are now arranged by their tour operators, generally outsourced through a catering company. Pilgrims whose tour operators do not organize their food often rely on street vendors and gastroenteritis incidences have been reported, either as an outbreak (Emamian and Mohammad Mohammadi 2013) or a clustering of reported cases (Al-Mazrou 2004).

Travelers' diarrhea has been shown to be an independent risk factor for contracting extended-spectrum B-lactamase (ESBL)-producing Enterobacteriaceae (ESBL-PE), with the rate of acquisition varying according to destination and age of the travelers (Kantele et al. 2015). Both the host country, Saudi Arabia, and countries that send pilgrims on Hajj are countries at higher risk for the acquisition of diarrheal illnesses (Steffen 2005; Steffen et al. 2015) and ESBL-PE infections (Kantele et al. 2015).

Abd El Ghany et al. (2017) have conducted the first large-scale epidemiological study to identify the etiologic agents of Hajj-associated diarrheal infections. The investigators used integrated antigenic and molecular approaches to screen 544 fecal samples from symptomatic pilgrims during three consecutive Hajj seasons for 16 pathogens associated with diarrheal infections. The data demonstrate that Hajjassociated diarrheal disease is associated with mild illnesses caused mainly by a single bacterial agent, with enterotoxigenic E. coli, Salmonella spp., and Shigellal entero-invasive E. coli (EIEC) being the major causes. Of particular concern were the presence of ESBL and carbapenemase genes in $\sim 40 \%$ of Salmonella spp. and $E$. coli-positive samples collected (Abd El Ghany et al. 2017).

In another study, an increase in the rate of carriage of third-generation cephalosporin-, gentamicin-, and colistin-resistant nontyphoidal Salmonella spp. (NTS) has been shown among French pilgrims on their return from performing Hajj (Olaitan et al. 2015). This is a matter of concern; third generation cephalosporins are considered the drug of choice in the treatment of many pediatric NTS infections (Wen et al. 2017), and overall, they are used as second-line of treatment for most typhoidal Salmonella spp. (WHO 2003). The proportion of third-generation cephalosporinresistant NST in Hajj settings is $33.3 \%$ of isolated NTS (Olaitan et al. 2015) and $40.3 \%$ of diarrhea-associated Salmonella spp. infections (Abd El Ghany et al. 2017), similar to what is recorded globally for NTS (31.2-55\%) (Burke et al. 2014; Murphy et al. 2018).

Enterotoxigenic E. coli (ETEC) is the most common serovar of E. coli and is commonly associated with foodborne diarrheal infections during traveling to endemic regions in Africa, Asia, and South America (Diemert 2006; Steffen 2017; Steffen et al. 2015). Many studies have illustrated the role of ETEC and other diarrheagenic E. coli strains in the occurrence of diarrheal infections and the emergence of outbreaks in MGs through catering (Kim et al. 2017; Ochi et al. 2017; Park et al. 2018). Approximately $33.3 \%$ of the $E$. coli-positive samples from symptomatic diarrheal cases at Hajj have been identified to contain $b l a_{\mathrm{CTX}-\mathrm{M}-15}$ and $b l a_{\mathrm{NDM}}$ genes that are associated with resistance to third-generation cephalosporins 
(Abd El Ghany et al. 2017). Such a high rate of third-generation cephalosporin resistance to E. coli in Hajj is only comparable with the higher end of the global range, which spans from as low as 3-7.8\% (Randrianirina et al. 2014; Seiffert et al. 2013) to as high as 40-48\% (Chagas et al. 2011; Lien et al. 2017; WHO 2003).

Another study found that $89 \%$ E. coli isolates during Hajj were resistant to ampicillin, 9\% to piperacillin/tazobactam, and 5\% to imipenem (Asghar 2006). The proportion of AMR E. coli at Hajj is greater than the global average. Globally, the proportion of $E$. coli that are resistant to imipenem is $\leq 1 \%$ (Badura et al. 2015; Lien et al. 2017), to piperacillin/tazobactam is $0.02-0.8 \%$ (Badura et al. 2015; Gonzalez and Cortes 2014), and to ampicillin is $40-82.1 \%$ (Badura et al. 2015; Randrianirina et al. 2014).

\section{Mobile Nature of Resistance Genes Found in Hajj Mass Gathering}

In Hajj, bla genes was found in Salmonella spp., E. coli, and A. baumannii with an average acquisition rate of $33.4 \%$, ranging from $22.2 \%$ to $40.3 \%$ (Abd El Ghany et al. 2017; Alyamani et al. 2017; Leangapichart et al. 2016b). Moreover, a study found that the bla gene was in $88.9 \%$ of amoxicillin-clavulanate and ampicillin-resistant $K$. pneumoniae isolates (Al-Zahrani and Alsiri 2018). The most commonly mentioned bla gene in available literature in Hajj is the $b l a_{\text {CTX-M-15 }}$ gene, associated with Salmonella spp. and E. coli (Abd El Ghany et al. 2017; Alyamani et al. 2017; Leangapichart et al. 2016b). Harboring other variations of $b l a_{\text {CTX-M }}$ gene (Alyamani et al. 2017; Leangapichart et al. 2016a, b, 2017), bla $a_{\mathrm{NDM}}$ (Abd El Ghany et al. 2017; Al-Zahrani and Alsiri 2018; Leangapichart et al. 2016b), bla $a_{\text {OXA }}$ (Al-Zahrani and Alsiri 2018; Alyamani et al. 2017; Leangapichart et al. 2016b), bla TEM $_{\text {(Alyamani et }}$ al. 2017; Leangapichart et al. 2016a, b), bla $a_{\mathrm{SHV}}$ (Alyamani et al. 2017; Leangapichart et al. 2016a), and bla $_{\mathrm{VIM}}$ (Al-Zahrani and Alsiri 2018) are also found in Hajj. No documented findings on Enterobacteriaceae harboring the $b l a_{\mathrm{KPC}}$ and bla $_{\mathrm{IMP}}$ genes in Hajj (Abd El Ghany et al. 2017; Al-Zahrani and Alsiri 2018).

During Hajj, of aminoglycoside-resistant $E$. coli isolates from hospitalized patients with urinary tract infection from two general hospitals in Makkah: 44.8\% harbored the aac 6 gene, $43 \%$ harbored the aac $6 \mathrm{Ib}$ gene, $42 \%$ harbored the aad 4 gene, $36 \%$ harbored the str $\mathrm{B}$ gene, $15 \%$ harbored the aad $\mathrm{A} 1$ gene, $12 \%$ harbored the aad $\mathrm{A} 2$ gene, $4 \%$ harbored the aad $\mathrm{B}$ gene, $4 \%$ harbored the ant 2 gene, $12 \%$ harbored the aphA gene, and 1\% harbored the strA gene (Alyamani et al. 2017).

The studies demonstrated that many Enterobacteriaceae members carrying plasmid-mediated resistance genes including ESBLs (e.g., $b l a_{\mathrm{CTX}-\mathrm{M}}$ ), Carbapenemases (e.g., bla $a_{\mathrm{NDM}}$ ), and Colistin are the major contributors to Hajj-associated enteric carriage and infections. This is not surprising considering the well-established fact that AMR in Gram-negative bacteria is associated with horizontal gene transfer mediated mainly by plasmids and conjugative transposons (Partridge 2011, 2015). This allow for AMR transmission through the dissemination of resistance plasmids among different strains and closely related species. 


\section{Drug Resistant Respiratory Infections in Hajj}

Unlike most other parts of Saudi Arabia, tuberculosis (TB) is considered endemic to the Makkah region, with a $25 \%$ incidence rate compared to around $16 \%$ for the rest of the country. While the incidence in most parts of the country has decreased, the rate of TB in Makkah has increased since the start of the Millennium (Al-Orainey 2013). Consequently, the rate of multidrug-resistant (MDR) TB is higher in the Makkah region (25\%) compared to that in other regions of Saudi Arabia (Al-Orainey 2013). Available data show that $1.4 \%$ of pilgrims from TB endemic countries have undiagnosed active TB (Yezli et al. 2017b) and a prospective study conducted in 2005 involving Singaporean pilgrims show that around 10\% pilgrims acquire TB following Hajj attendance (Wilder-Smith et al. 2005). In a study of hospitalized patients diagnosed with pneumonia during Hajj 1994, TB was found to be the leading cause, accounting for $20 \%$ of pneumonia cases (Alzeer et al. 1998). While no drug resistance was reported (Yezli et al. 2017b), given the risk of transmission from cases that are not being identified as TB and treated accordingly, the situation is alarming.

The serogroup W Neisseria meningitidis strain responsible for the Hajj-associated intercontinental meningococcal outbreak of 2000 and 2001 was resistant to several antimicrobials, including sulfadiazine, cloxacillin, tetracycline, and cotrimoxazole (trimethoprim/sulfamethoxazole) (Abd El Ghany et al. 2016; Molling et al. 2001; Yousuf and Nadeem 1995). Reported levels of drug resistance for Neisseria meningitidis infections related to Hajj were 10.3\% for azithromycin, 5.9\% for ciprofloxacin, 4.4\% for levofloxacin, 4.4\% for rifampicin (Ashgar et al. 2013), and $66.6 \%$ for gentamycin (Karima et al. 2003). While Hajj-associated meningococcal strains are still susceptible to penicillin, cephalosporins, ciprofloxacin (Karima et al. 2003), and cefotaxime (Ashgar et al. 2013), their epidemiology may change over time. This is also true for Umrah pilgrimage; the meningococcal colonization rate among Umrah visitors was found to have doubled by the end of the pilgrimage compared with the beginning (Ashgar et al. 2013). Hence, alternative strategies, such as the impact of vaccination on the meningococcal AMR profile, need to be explored.

Streptococcus pneumoniae is a Gram-positive bacterium responsible for an array of noninvasive and invasive diseases, including sepsis and meningitis. Pneumonia is the leading cause of hospital admission during Hajj (Ridda et al. 2014). Different pneumococcal vaccine types are available, with recommended target groups for each type (Abd El Ghany et al. 2016; CDC 2012). Currently, pneumococcal vaccination is not a visa requirement for Hajj attendance, but it is recommended for high-risk pilgrims (Abd El Ghany et al. 2016). The carriage rate of Hajj-related S. pneumoniae among international pilgrims was $5.4 \%$, of which $76.7 \%$ of the isolates were reported to be resistant to at least one drug and $22.9 \%$ to three or more drugs (Memish et al. 2015, 2016). These rates are higher than what is reported globally (5-50\%) for at least one drug but on the upper end of the range of globally reported MDR S. pneumoniae (9-24\%) (Lynch and Zhanel 2010). In view of the much lower carriage rates typically seen globally among community-dwelling adults, the levels 
of drug resistance seen for $S$. pneumoniae during Hajj are alarming and require further investigations.

Staphylococcus spp. are Gram-positive bacteria that usually colonize human skin and nasal flora. Staphylococcus aureus is one of the leading causes of bacteremia and is associated with skin and other related infections (Tong et al. 2015). Methicillinresistant $S$. aureus (MRSA) infections are more serious because they are typically more difficult to treat. Globally, over $90 \%$ of Staphylococcus aureus are resistant to penicillin (Lowy 2003). Globally for general communities, MRSA colonization rate is $1.25 \%$, accounting for $5.68 \%$ of isolated S. aureus (Shokouhi et al. 2017). In Hajj, the reported rates are slightly higher; MRSA colonization is $1.46 \%$, accounting for $7.1 \%$ of noninvasive $S$. aureus isolates in Hajj (Memish et al. 2006). Paradoxically, MRSA colonization rates in Hajj are lower when compared to close-quarter living communities; where MRSA colonization rate is $6.1 \%$, accounting for $21.7 \%$ of S. aureus isolates (Mobasherizadeh et al. 2016). This lower carriage rate has been partially attributed to the prophylactic measures (including antimicrobial use) used before the start of Hajj (Memish et al. 2006).

In Makkah hospitals, S. aureus bacteremia incidence increases during the Hajj season compared with other parts of the year (Asghar 2006), with 43.3\% of bacteremia isolates been identified as Staphylococci spp., of which $43 \%$ were identified as $S$. aureus (Asghar 2006). S. aureus isolates from bacteremia patients during Hajj were resistant to several antimicrobials: $92 \%$ to penicillin, $79 \%$ to ampicillin, $58 \%$ to cotrimoxazole, $56 \%$ to erythromycin, $53 \%$ to oxacillin, $49 \%$ to cephalothin, $48 \%$ to clindamycin, $44 \%$ to gentamycin, $42 \%$ to cefoxitin, and $38 \%$ to amoxicillin/clavulanate. MDR MRSA, resistance to three or more of the following agents: erythromycin, clindamycin, gentamicin, and oxytetracycline was identified in 30.7\% of Staphylococcus aureus isolates (Asghar 2006). Moreover, the rate of AMR Staphylococcus aureus responsible for causing bacteremia among Hajj pilgrim is higher than the resistance rate found globally against oxacillin (36\%) and cotrimoxazole (43.7\%) (Musicha et al. 2017). These data are alarming because $\beta$-lactams, such as oxacillin, are the first line of drugs of choice when treating S. aureus bacteremia (Thwaites et al. 2011).

S. aureus is a common organism for causing pyoderma, a skin infection, during Hajj seasons (Fatani et al. 2002). Pyoderma accounts for 5.6\% of dermatological cases in Hajj, with $47.5 \%$ of pyoderma cases being caused by $S$. aureus. Many pyoderma $S$. aureus isolates among Hajj pilgrims are resistant to a range of antimicrobials: $80.9 \%$ resistant to penicillin, $12.8 \%$ to tetracycline, $6.4 \%$ to gentamicin, $4.3 \%$ each to erythromycin, cotrimoxazole, and clindamycin, and $2.1 \%$ each to cephalothin and oxacillin (Fatani et al. 2002).

\section{Conclusions}

The Arab world is a geographical hub in the flow of people, cash, and commodities. The mass gathering (MG) events that occur in the region can greatly impact global health. Antimicrobial resistance (AMR) during MG has been shown to affect both 
home and guest countries, with pathogens and colonizers being freely transmitted and, therefore, a risk of AMR acquisition and dissemination. The field of MGM is still being established and there are limited data on AMR among attendees of MGs. A combination of regional conflicts, a low scientific funding base, and restrictions on foreign investigators into MG studies all contribute to this knowledge gap. The available studies suggest that the rate of AMR among attendees of MGs in the Arab region is high and increasing. Further studies are needed for a clear picture of the AMR profile in MGs, and specifically in Hajj, and assess how the widespread use of prophylactic and over-the-counter antimicrobials is impacting this. Evaluating the effects of vaccination on AMR of both disease-causing and colonizing organisms is also a research priority. Moving forward, the governments of the host countries of MGs will need to work in a cross-government capacity, including the relevant ministries of human and animal health, infrastructure, and planning, and will also need to work in an inter-government capacity with supranational agencies and the governments of participating travelers. This will require collaboration that goes beyond the International Health Regulation requirements, with a focus on transparency and information-sharing.

\section{References}

Abd El Ghany M, Sharaf H, Hill-Cawthorne GA (2016) Hajj vaccinations - facts, challenges, and hope. Int J Infect Dis 47:29-37. https://doi.org/10.1016/j.ijid.2016.05.024

Abd El Ghany M et al (2017) Enteric infections circulating during Hajj seasons, 2011-2013. Emerg Infect Dis 23:10. https://doi.org/10.3201/eid2310.161642

Abd El Ghany M, Al-Tawfiq JA, Hill-Cawthorne GA, Memish ZA (2018) Hajj - beyond traveller's diarrhea. Travel Med Infect Dis 21:80-81. https://doi.org/10.1016/j.tmaid.2017.11.004

Ahmed QA, Arabi YM, Memish ZA (2006) Health risks at the Hajj. Lancet 367:1008-1015. https:// doi.org/10.1016/S0140-6736(06)68429-8

Al-Lami F et al (2013) Pattern of morbidity and mortality in Karbala hospitals during Ashura mass gathering at Karbala, Iraq, 2010. East Mediterr Health J 19:S13-S18

Al-Mazrou YY (2004) Food poisoning in Saudi Arabia. Potential for prevention? Saudi Med J 25:11-14

Al-Orainey IO (2013) Tuberculosis infection during Hajj pilgrimage. The risk to pilgrims and their communities. Saudi Med J 34:676-680

Alyamani EJ, Khiyami AM, Booq RY, Majrashi MA, Bahwerth FS, Rechkina E (2017) The occurrence of ESBL-producing Escherichia coli carrying aminoglycoside resistance genes in urinary tract infections in Saudi Arabia. Ann Clin Microbiol Antimicrob 16:1. https://doi.org/ 10.1186/s12941-016-0177-6

Al-Zahrani IA, Alsiri BA (2018) The emergence of carbapenem-resistant Klebsiella pneumoniae isolates producing OXA-48 and NDM in the Southern (Asir) province, Saudi Arabia. Saudi Med J 39:23-30. https://doi.org/10.15537/smj.2018.1.21094

Alzeer A, Mashlah A, Fakim N, Al-Sugair N, Al-Hedaithy M, Al-Majed S, Jamjoom G (1998) Tuberculosis is the commonest cause of pneumonia requiring hospitalization during Hajj (pilgrimage to Makkah). J Infect 36:303-306

Arcilla MS et al (2017) Import and spread of extended-spectrum beta-lactamase-producing Enterobacteriaceae by international travellers (COMBAT study): a prospective, multicentre cohort study. Lancet Infect Dis 17:78-85 
Asghar AH (2006) Frequency and antimicrobial susceptibility patterns of bacterial pathogens isolated from septicemic patients in Makkah hospitals. Saudi Med J 27:361-367

Ashgar SS et al (2013) Prevalence of nasal carriage of Neisseria meningitidis among Umrah visitors and pilgrims during Umrah and Hajj season. Glob Adv Res J Microbiol 2:141-149

Badura A, Feierl G, Pregartner G, Krause R, Grisold AJ (2015) Antibiotic resistance patterns of more than 120000 clinical Escherichia coli isolates in Southeast Austria, 1998-2013. Clin Microbiol Infect 21:569.e561-569.e567. https://doi.org/10.1016/j.cmi.2015.02.012

Brown K, Uwiera RRE, Kalmokoff ML, Brooks SPJ, Inglis GD (2017) Antimicrobial growth promoter use in livestock: a requirement to understand their modes of action to develop effective alternatives. Int J Antimicrob Agents 49:12-24. https://doi.org/10.1016/j. ijantimicag.2016.08.006

Burke L, Hopkins KL, Meunier D, de Pinna E, Fitzgerald-Hughes D, Humphreys H, Woodford N (2014) Resistance to third-generation cephalosporins in human non-typhoidal Salmonella enterica isolates from England and Wales, 2010-12. J Antimicrob Chemother 69:977-981. https://doi.org/10.1093/jac/dkt469

CDC (2012) Use of 13-valent pneumococcal conjugate vaccine and 23-valent pneumococcal polysaccharide vaccine for adults with immunocompromising conditions: recommendations of the Advisory Committee on Immunization Practices (ACIP). MMWR Morb Mortal Wkly Rep 61:816

Chagas TP, Seki LM, Cury JC, Oliveira JA, Davila AM, Silva DM, Asensi MD (2011) Multiresistance, beta-lactamase-encoding genes and bacterial diversity in hospital wastewater in Rio de Janeiro, Brazil. J Appl Microbiol 111:572-581. https://doi.org/10.1111/j.13652672.2011.05072.x

Chan M (2011) WHO: World Health Day 2011 message by Dr Margaret Chan

Coutts A, Stuckler D, Batniji R, Ismail S, Maziak W, McKee M (2013) The Arab Spring and health: two years on. Int J Health Serv 43:49-60

De Lorenzo RA, Boyle MF, Garrison R (1993) A proposed model for a residency experience in mass gathering medicine: the United States air show. Ann Emerg Med 22:1711-1714

de Smalen AW, Ghorab H, Abd El Ghany M, Hill-Cawthorne GA (2017) Refugees and antimicrobial resistance: A systematic review. Travel Med Infect Dis 15:23-28

Diemert DJ (2006) Prevention and self-treatment of traveler's diarrhea. Clin Microbiol Rev 19:583-594. https://doi.org/10.1128/cmr.00052-05

Emamian MH, Mohammad Mohammadi G (2013) An outbreak of gastroenteritis among Iranian pilgrims of Hajj during 2011. Iran Red Crescent Med J 15:317-319. https://doi.org/10.5812/ ircmj.3681

Fatani MI, Bukhari SZ, Al-Afif KA, Karima TM, Abdulghani MR, Al-Kaltham MI (2002) Pyoderma among Hajj pilgrims in Makkah. Saudi Med J 23:782-785. (Erratum appears in Saudi Med J 2002 23(10):1296)

Fleming A (1929) On the antibacterial action of cultures of a penicillium, with special reference to their use in the isolation of B. influenzae. Br J Exp Pathol 10:226-236

Gautret P, Steffen R (2016) Communicable diseases as health risks at mass gatherings other than Hajj: what is the evidence? Int J Infect Dis 47:46-52. https://doi.org/10.1016/j.ijid.2016.03.007

Gautret P, Benkouiten S, Sridhar S, Al-Tawfiq JA, Memish ZA (2015) Diarrhea at the Hajj and Umrah. Travel Med Infect Dis 13:159-166. https://doi.org/10.1016/j.tmaid.2015.02.005

Ghasemian R, Babamahmoodi F, Ahangarkani F (2016) Hepatitis A is a health hazard for Iranian pilgrims who go to Holly Karbala: a preliminary report. Hepat Mon 16:e38138. https://doi.org/ 10.5812/hepatmon. 38138

Gonzalez L, Cortes JA (2014) Systematic review of antimicrobial resistance in Enterobacteriaceae isolates from Colombian hospitals. Biomedica 34:180-197. https://doi.org/10.1590/s012041572014000200005

Grgic-Vitek M, Frelih T, Ucakar V, Fafangel M, Jordan Markocic O, Prosenc K, Kraigher A (2015) An outbreak of measles associated with an international dog show in Slovenia, November 2014. Euro Surveill 20:pii: 21012 
Horwitz MA, Pollard RA, Merson MH, Martin SM (1977) A large outbreak of foodborne salmonellosis on the Navajo Nation Indian Reservation, epidemiology and secondary transmission. Am J Public Health 67:1071-1076

$\mathrm{Hu} \mathrm{D}$ et al (2016) Origins of the current seventh cholera pandemic. Proc Natl Acad Sci U S A 113:E7730-E7739. https://doi.org/10.1073/pnas.1608732113

Hussein NH (2017) Emergence of NDM-1 among carbapenem-resistant Klebsiella pneumoniae in Iraqi hospitals. Acta Microbiol Immunol Hung:1-17. https://doi.org/10.1556/030.64.2017.026

Kantele A et al (2015) Antimicrobials increase travelers' risk of colonization by extended-spectrum betalactamase-producing Enterobacteriaceae. Clin Infect Dis 60:837-846. https://doi.org/ 10.1093/cid/ciu957

Karima TM, Bukhari SZ, Fatani MI, Yasin KA, Al-Afif KA, Hafiz FH (2003) Clinical and microbiological spectrum of meningococcal disease in adults during Hajj 2000: an implication of quadrivalent vaccination policy. JPMA J Pak Med Assoc 53:3-7

Khachatourians GG (1998) Agricultural use of antibiotics and the evolution and transfer of antibiotic-resistant bacteria. Can Med Assoc J 159:1129-1136

Kim JS et al (2017) Outbreak of CTX-M-15-producing enterotoxigenic Escherichia coli O159:H20 in the Republic of Korea in 2016. Antimicrob Agents Chemother 61:pii: e00339-17

Leangapichart T, Dia NM, Olaitan AO, Gautret P, Brouqui P, Rolain J-M (2016a) Acquisition of extended-spectrum $\beta$-lactamases by Escherichia coli and Klebsiella pneumoniae in gut microbiota of pilgrims during the Hajj pilgrimage of 2013. Antimicrob Agents Chemother 60:3222-3226. https://doi.org/10.1128/AAC.02396-15

Leangapichart T, Gautret P, Griffiths K, Belhouchat K, Memish Z, Raoult D, Rolain JM (2016b) Acquisition of a high diversity of bacteria during the Hajj pilgrimage, including Acinetobacter baumannii with blaOXA-72 and Escherichia coli with blaNDM-5 carbapenemase genes. Antimicrob Agents Chemother 60:5942-5948. https://doi.org/10.1128/AAC.00669-16

Leangapichart T, Tissot-Dupont H, Raoult D, Memish ZA, Rolain J-M, Gautret P (2017) Risk factors for acquisition of CTX-M genes in pilgrims during Hajj 2013 and 2014. J Antimicrob Chemother 72:2627-2635. https://doi.org/10.1093/jac/dkx155

Lien LTQ et al (2017) Antibiotic resistance and antibiotic resistance genes in Escherichia coli isolates from hospital wastewater in Vietnam. Int J Environ Res Public Health 14:699. https:// doi.org/10.3390/ijerph14070699

Lowy FD (2003) Antimicrobial resistance: the example of Staphylococcus aureus. J Clin Invest 111:1265-1273. https://doi.org/10.1172/JCI200318535

Lynch JP III, Zhanel GG (2010) Streptococcus pneumoniae: epidemiology and risk factors, evolution of antimicrobial resistance, and impact of vaccines. Curr Opin Pulm Med 16:217-225. https://doi.org/10.1097/MCP.0b013e3283385653

Memish ZA, Balkhy HH, Almuneef MA, Al-Haj-Hussein BT, Bukhari AI, Osoba AO (2006) Carriage of Staphylococcus aureus among Hajj pilgrims. Saudi Med J 27:1367-1372

Memish ZA et al (2015) Impact of the Hajj on pneumococcal transmission. Clin Microbiol Infect 21:77.e11-77.e18. https://doi.org/10.1016/j.cmi.2014.07.005

Memish ZA et al (2016) A cohort study of the impact and acquisition of naspharyngeal carriage of Streptococcus pneumoniae during the Hajj. Travel Med Infect Dis 14:242-247. https://doi.org/ 10.1016/j.tmaid.2016.05.001

Michael JA, Barbera JA (1997) Mass gathering medical care: a twenty-five year review. Prehosp Disaster Med 12:72-79. https://doi.org/10.1017/S1049023X00037857

Mobasherizadeh S et al (2016) Nasal carriage screening of community-associated methicillin resistant Staphylococcus aureus in healthy children of a developing country. Adv Biomed Res 5:144. https://doi.org/10.4103/2277-9175.187400

Molling P, Backman A, Olcen P, Fredlund H (2001) Comparison of serogroup W-135 meningococci isolated in Sweden during a 23-year period and those associated with a recent Hajj pilgrimage. J Clin Microbiol 39:2695-2699

Moore PS, Reeves MW, Schwartz B, Gellin BG, Broome CV (1989) Intercontinental spread of an epidemic group A Neisseria meningitidis strain. Lancet 2:260-263 
Moubareck CA et al (2018) Clonal emergence of Klebsiella pneumoniae ST14 co-producing OXA48-type and NDM carbapenemases with high rate of colistin resistance in Dubai, United Arab Emirates. Int J Antimicrob Agents. https://doi.org/10.1016/j.ijantimicag.2018.03.003

Murphy CN, Fowler RC, Williams AJ, Iwen PC, Fey PD (2018) Nontyphoidal Salmonella enterica nonsusceptible to both levofloxacin and ceftriaxone in Nebraska, United States 2014-2015. Foodborne Pathog Dis. https://doi.org/10.1089/fpd.2017.2361

Musicha $\mathrm{P}$ et al (2017) Trends in antimicrobial resistance in bloodstream infection isolates at a large urban hospital in Malawi (1998-2016): a surveillance study. Lancet Infect Dis 17:1042-1052. https://doi.org/10.1016/S1473-3099(17)30394-8

Nasr Z, Paravattil B, Wilby KJ (2017) The impact of antimicrobial stewardship strategies on antibiotic appropriateness and prescribing behaviours in selected countries in the Middle East: a systematic review. East Mediterr Health J 23:430-440

O'Neill J (2014) Antimicrobial resistance: tackling a crisis for the health and wealth of nations. Rev Antimicrob Resist. https://amr-review.org/Publications.html

O’Neill J (2016) Tackling drug-resistant infections globally: final report and recommendations. Rev Antimicrob Resist. https://amr-review.org/Publications.html

Ochi S et al (2017) An outbreak of diarrhea in Mandera, Kenya, due to Escherichia coli serogroup $\mathrm{O}$-nontypable strain that had a coding gene for enteroaggregative $E$. coli heat-stable enterotoxin 1. Am J Trop Med Hyg 96:457-464

Olaitan AO et al (2015) Acquisition of extended-spectrum cephalosporin- and colistin-resistant Salmonella enterica subsp. enterica serotype Newport by pilgrims during Hajj. Int J Antimicrob Agents 45:600-604. https://doi.org/10.1016/j.ijantimicag.2015.01.010

Pagel SW, Gautier P (2012) Use of antimicrobial agents in livestock. Rev Sci Tech 31:145-188

Park J et al (2018) A waterborne outbreak of multiple diarrhoeagenic Escherichia coli infections associated with drinking water at a school camp. Int J Infect Dis 66:45-50

Partridge SR (2011) Analysis of antibiotic resistance regions in Gram-negative bacteria. FEMS Microbiol Rev 35:820-855. https://doi.org/10.1111/j.1574-6976.2011.00277.x

Partridge SR (2015) Resistance mechanisms in Enterobacteriaceae. Pathology 47:276-284. https:// doi.org/10.1097/pat.0000000000000237

Pesola AK et al (2015) Multinational outbreak of Salmonella enteritidis infection during an international youth ice hockey competition in Riga, Latvia, preliminary report, March and April 2015. Euro Surveill 20:pii: 21133

Pfaff G, Lohr D, Santibanez S, Mankertz A, van Treeck U, Schonberger K, Hautmann W (2010) Spotlight on measles 2010: measles outbreak among travellers returning from a mass gathering, Germany, September to October 2010. Euro Surveill 15:pii: 19750

Phillips I (2007) Withdrawal of growth-promoting antibiotics in Europe and its effects in relation to human health. Int J Antimicrob Agents 30:101-107. https://doi.org/10.1016/j. ijantimicag.2007.02.018

Rahim HF et al (2014) Non-communicable diseases in the Arab world. Lancet 383:356-367. https://doi.org/10.1016/s0140-6736(13)62383-1

Randrianirina F et al (2014) Antimicrobial resistance of bacterial enteropathogens isolated from stools in Madagascar. BMC Infect Dis 14:104-104. https://doi.org/10.1186/1471-2334-14-104

Ridda I, King C, Rashid H (2014) Pneumococcal infections at Hajj: current knowledge gaps. Infect Disord Drug Targets 14:177-184

Seiffert SN, Hilty M, Kronenberg A, Droz S, Perreten V, Endimiani A (2013) Extended-spectrum cephalosporin-resistant Escherichia coli in community, specialized outpatient clinic and hospital settings in Switzerland. J Antimicrob Chemother 68:2249-2254. https://doi.org/10.1093/jac/ dkt208

Shokouhi S, Darazam IA, Zamanian M-H (2017) Community-acquired methicillin-resistant Staphylococcus aureus carriage rate and antimicrobial susceptibility in a tertiary center, Iran. J Res Med Sci 22:71. https://doi.org/10.4103/jrms.JRMS 83316

Steffen R (2005) Epidemiology of traveler's diarrhea. Clin Infect Dis 41(Suppl 8):S536-S540. https://doi.org/10.1086/432948 
Steffen R (2017) Epidemiology of travellers' diarrhea. J Travel Med 24:S2-s5. https://doi.org/ 10.1093/jtm/taw072

Steffen R, Hill DR, DuPont HL (2015) Traveler's diarrhea: a clinical review. JAMA 313:71-80. https://doi.org/10.1001/jama.2014.17006

Thwaites GE et al (2011) Clinical management of Staphylococcus aureus bacteraemia. Lancet Infect Dis 11:208-222. https://doi.org/10.1016/S1473-3099(10)70285-1

Tong SYC, Davis JS, Eichenberger E, Holland TL, Fowler VG (2015) Staphylococcus aureus infections: epidemiology, pathophysiology, clinical manifestations, and management. Clin Microbiol Rev 28:603-661. https://doi.org/10.1128/CMR.00134-14

Udo EE, Boswihi SS (2017) Antibiotic resistance trends in methicillin-resistant Staphylococcus aureus isolated in Kuwait hospitals: 2011-2015. Med Princ Pract 26:485-490. https://doi.org/ $10.1159 / 000481944$

Vintras L (1894) On the temporary suspension of the pilgrimage to Mecca as a preventive measure against cholera. Br Med J 1:460-461

Wen SC, Best E, Nourse C (2017) Non-typhoidal Salmonella infections in children: review of literature and recommendations for management. J Paediatr Child Health 53(10):936-941

WHO (2003) Background document: the diagnosis, treatment and prevention of typhoid fever. World Health Organisation (WHO), Geneva

WHO (2008) Communicable disease alert and response for mass gatherings: key considerations. World Health Organization (WHO), Geneva

WHO (2014) Antimicrobial resistance: global report on surveillance. World Health Organization (WHO), Geneva

WHO (2015a) Public health for mass gatherings: key considerations. World Health Organization (WHO), Geneva

WHO (2015b) Worldwide country situation analysis: response to antimicrobial resistance. World Health Organization (WHO), Geneva

WHO (2016) International Health Regulations (2005), 3rd edn. World Health Organization (WHO), Geneva

WHO (2017a) Global tuberculosis report 2017. World Health Organization (WHO), Geneva

WHO (2017b) MERS-CoV global summary and assessment of risk. World Health Organization (WHO), Geneva

WHO (2017c) WHO guidelines on use of medically important antimicrobials in food-producing animals. World Health Organization (WHO), Geneva

WHO (2017d) World malaria report 2017. World Health Organization (WHO), Geneva

WHO Secretariat (2011) Global mass gatherings: implications and opportunities for global health security. World Health Organization (WHO), Geneva

Wilder-Smith A, Foo W, Earnest A, Paton NI (2005) High risk of Mycobacterium tuberculosis infection during the Hajj pilgrimage. Tropical Med Int Health 10:336-339. https://doi.org/ 10.1111/j.1365-3156.2005.01395.x

Yezli S, Yassin Y, Awam A, Attar A, Al-Jahdali E, Alotaibi B (2017a) Umrah. An opportunity for mass gatherings health research. Saudi Med J 38:868-871. https://doi.org/10.15537/ smj.2017.8.20124

Yezli S, Zumla A, Yassin Y, Al-Shangiti AM, Mohamed G, Turkistani AM, Alotaibi B (2017b) Undiagnosed active pulmonary tuberculosis among pilgrims during the 2015 Hajj mass gathering: a prospective cross-sectional study. Am J Trop Med Hyg 97:1304-1309. https://doi.org/ 10.4269/ajtmh.17-0271

Yousuf M, Nadeem A (1995) Fatal meningococcaemia due to group W135 amongst Haj pilgrims: implications for future vaccination policy. Ann Trop Med Parasitol 89:321-322 